\title{
Investigación
}

\section{Noise induced and noise exposure hearing loss}

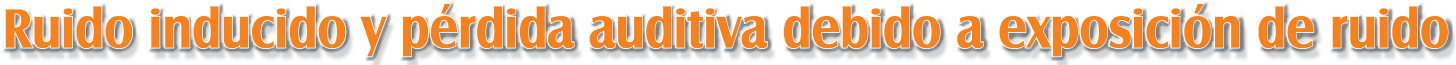

\begin{abstract}
The work describes the main mechanisms of noise exposure and its consequences, mainly induced hearing loss. Destruction of the inner ear, especially diminution of the number of hair cells inside the Corti's organ, is closely linked to hearing loss. Data analysis yield to the conclusion that relevant variables in this problem are, among others, occupation, gender, exposure time and age group. Based on theoretical and experimental facts, a regression model is constructed, which characterizes the probability of hearing loss upon the mentioned parameters.
\end{abstract}

\section{Keywords}

Noise exposure, Hearing loss, Equivalent Noise Level, Otoacoustic emissions.

\section{Resumen}

El presente trabajo describe los mecanismos principales de exposición de ruido y sus consecuencias, principalmente pérdida de audición inducida. La destrucción del oído interno, especialmente la disminución del número de ciliadas dentro del Órgano de Corti, está íntimamente relacionado con la pérdida auditiva. El análisis de los datos lleva a la

M. Sc. Desarrollo Sostenible y Medio Ambiente. Químico, especialista en Ingeniería Sanitaria y Ambiental, docente catedrático de la Ph. D. (c), Universidad de Otago, Nueva Zelanda Graduada, M. Sc. Gerencia de la Información, Universidad de Medellín. Pertenece al grupo de investigación de la Universidad de Otago, denominado Centre for Sustainability (CSAFE). E-mail: girdi290@student.otago.ac.nz. 
conclusión que las variables relevantes en este problema son, entre otras, la ocupación, el género, el tiempo de exposición y el grupo de edades. Basado en hechos teóricos y experimentales, un modelo de regresión es construido, el cual caracteriza la probabilidad de pérdida auditiva en función de los parámetros mencionados.

\section{Palabras clave}

Exposición al ruido, pérdida de audición, nivel de ruido equivalente, emisiones otoacústicas.

\section{Introduction}

Noise induced hearing loss is a chronic illness that eventually becomes irreversible. This is due to the permanent disruption of the organ Corti. This organ contains hairs that are constantly stimulated because they are irritated. The brain perceives this constant irritation as sound [1]. This irritation is gradual and cumulative, getting worse over time, becoming stable when the exposure to the noise is eliminated. The individual with auditory loss could develop conscription and tinnitus. There is also the possibility of a reduction of speech intelligibility, harming verbal communication [2].

Potentially the main cause of serious and irreversible injuries in the human hearing system (HHS) is attributed to noise [3]. This is known as noise induced hearing loss (NIHL). According to previous studies, impulsive noise is likely to be more harmful than steady-state noise [4]. Therefore, high levels of noise for short time periods can lead to early NIHL; however, 7-9\% of individuals, exposed to occupational noise levels of $85 \mathrm{dBA}$ or higher during daily periods of eight hours, have gradual deterioration of the auditory sensitivity i.e; cochlear damage. This damage can contribute towards notable hearing loss after a 10-year exposure period $[5,6]$. Other personal risk factors that have contributed to NIHL are: history of ear diseases, non-occupational noise exposure, cigarette smoking, use of hearing protection devices (HPDs), past history of noise exposure [7], hypertension [8, 9], exposure to vibrations, ototoxic drug use and certain chemicals. Even including these influences the association that noise has with hearing loss still remains robust [10].

Despite the existence of noise in the work environment, NIHL is a preventable disease. $\mathrm{NIHL}$ occurs when there is a lack of risk control or inadequate conditions of work [2].

This systematic review is intended to model the relationship between noise exposure and hearing loss. The reader is informed of the potential contributing causes to hearing loss by occupation, noise exposure, gender, age, time exposure, and other possible factors.

Specifically, this review demonstrates that noise exposure greater than $85 \mathrm{~dB}$ is the main cause of hearing loss. At the same time, this review takes into account control groups not exposed to noise, or who have adequate ear protection, and assesses the difference between the non-exposed group and exposed control groups. Therefore, this data can be used to determine appropriate implementation of policies in the labour sector. This information can also provide optimal hearing safeguards as necessary to reduce the risk or impact of hearing loss. 
The seven proven questions specific to this review are as follows:

1. What is the likelihood of persons exposed to noise exposure greater than $85 \mathrm{~dB}$ of developing hearing loss?

2. What is the likelihood of hearing loss on male occupation greater than women occupation?

3. What is the likelihood of induced hearing loss being affected by occupation/noise exposure?

4. What is the likelihood of hearing loss decreasing as the time of exposure increases?

5. Is there evidence of preventing hearing loss being by wearing ear protection? (This will be good to discuss a for further studies will be good to know although to the lack of this information, an analysis was not feasible).

\section{Methods}

This systematic review was carried out in accordance with the MOOSE Guidelines for Meta-Analyses and Systematic Reviews of Observational Studies [11]. These studies were selected from well-known Public and Medical health peer-review journals. The terms and keywords were combined with the Boolean search operator and/or as follows:

"ONIHL» or "NIHL» and "humans», and languages in "English or Spanish» and studies in full text journals concerning humans. The headings and subheadings selected were: Pure tone Audiometry hearing thresholds, Noise exposure, Hearing loss, Noise Injury and Noise deafness. Disregarded were the results of pure audiometry tone related to otoacustic emissions. Adults were included and temporary threshold was rejected. Genetic basis were also excluded.

\section{Eligibility criteria}

This data was selected from full text documents, excluding those which were only abstracts. These results were also related to permanent threshold shifts hearing loss. To capture as many relevant citations as possible, we researched analyses in both English and Spanish languages. With librarian assistance, systematic searches were undertaken from the following databases; MEDLINE, EMBASE, Web of Science (Public Environmental occupational health-Categories), Scopus (subjects area: medicine and health professions), document type articles, Cinhal (Major concepts such as: hearing loss, noise induced, hearing loss, conductive-hearing loss, sensorineural. Following by subheadings, classification, diagnosis, epidemiology, prevention and control and risk factors. Linking full text and excluding records from September 2009 to current. The purpose of this research was to identify studies on the effects of either occupational noise induced hearing loss $(\mathrm{ONIHL})$ or, Noise Induced hearing loss ( $\mathrm{NIHL})$. All occupations were taken into account for this analysis. 
The selection criteria for including sources contained, occupation, hearing loss results where the major frequency of pure-tone audiometry test was at $4 \mathrm{KHz}$. However, where those frequency results were not found, the results included had hearing loss levels of different evaluated frequencies from 3 to $8 \mathrm{KHz}$. Other results included mean hearing loss greater than 10 or 20 decibels, or, results encompassing the different levels of hearing loss as follows:

- $\quad$ Mild hearing loss from 25 to $40 \mathrm{~dB} \mathrm{HL}$

- Moderate to severe hearing loss from 41 to $70 \mathrm{~dB} \mathrm{HL}$

- Severe hearing loss from 71 to $90 \mathrm{~dB} \mathrm{HL}$

- Profound hearing loss greater than 90 dB HL (Clark, 1981 - American Speech-Language-Hearing Association (ASHA).

Occupational hearing loss studies are related to subjects who have been exposed to noise and induced noise hearing loss in different situations in the work place. Pure-tone audiometry is evidence-based on the results of the studies. Where possible, range of age is categorized by $15-29,30-44,45-59,60-69,70-79$, and $>80$ years. The average level per day of 8 hours, will be calculated when reported noise exposure is by hours instead of by day. Full time workers were targeted, including part time jobs and excluding those related to night clubs part time jobs. In addition, recreational noise exposure presbycusis (aging) and ear disease otopathology were analyzed.

Noise exposure measured by study dosimeters in $\mathrm{dB}$ will be given scores of $1,2,3$, and 4; with 4 being exposure to higher noise levels (greater than 100dB) and 1 exposure to less intense occupational noise ( $85-89 \mathrm{~dB})$. In studies where noise exposure measurement by dosimeter is not reported, each study is assigned a risk group by occupation-based on noise exposure reported by occupation in other meta-analyses and literature reviews. It is also important to identify and include measurements reported by control groups who have not been exposed to noise. This population, according to the American National Standards Institute (ANSI) were either exposed to low levels of noise or participated in an excellent hearing conservation program (HCP). Therefore, it is important to determine the NIHL (occupational noise) exposure and impact, including the control group-non-exposure (noise $<85 \mathrm{~dB}$ ) that scored 5 .

\section{Data Extraction}

Standardized abstraction sheet in excel (v.2010) were employed for recording of data from individual studies. Main characteristics extracted from each study and subsequently recorded in a data base evidence table included: author, year of publication, sample population, risk group (noise exposure level), age, gender, hearing level/type of test and study primary and secondary outcomes. All the statistical analyses were conducted in the statistical program SPSS (version 19.0.0.0; 2001-2003 The Apache Software Foundation)12. 


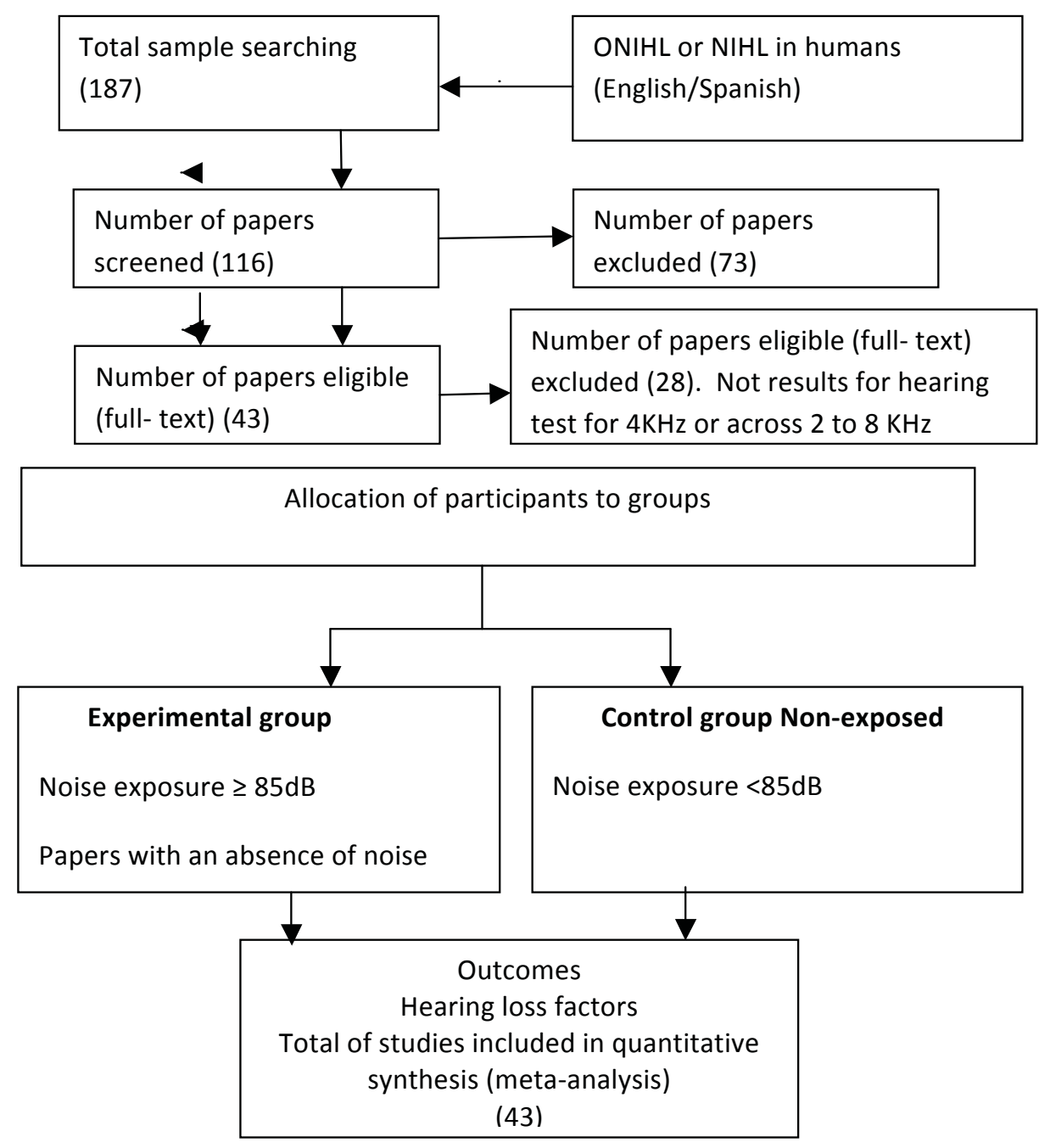

Figure 1. Flowchart of the number of articles in different stages of the selection strategy.

\section{Data Analysis}

The existence of hearing loss was defined as a weighted pure tone average (PTA) $>25 \mathrm{~dB} \mathrm{HL}$ at $4 \mathrm{KHz}$ frequency or across 3 to $8 \mathrm{kHz}$. Logistic regression was applied to determine odds ratios by occupation, gender, use of hearing protection and time exposure. Secondary outcomes to be analyzed will include use of hearing protection, time exposure to noise, age group, and gender where available.

Occupations have been allocated by levels noise exposure and to the following economic sectors: Air, Navy \& Army, transport, mining, manufacturing, maintenance personnel, services, agriculture, construction, fire-policemen, and workers who were non-exposed to noise defined as controls with noise exposure levels less than $85 \mathrm{~dB}$.

Time exposure was categorized depending on time exposure in years such as: $1(<2$ years), 2 (2-4 years), 3 (5-9 years), and 4 (>10 years) (ref). However, there is a shorter 
time of period of hearing loss when the sound is louder13 for instance workers exposed to firearms sound.

In relation to protection it has been assessed the dynamics of hearing loss of workers wearing protection against those who did not wear or worn in different intervals.

In cases of reported data of noise exposure by hours instead of by day, analysis of variance is applied to calculate an average level per day of 8 hours.

\section{Results}

Descriptive statistics of the distribution of hearing loss by Occupational Hearing Loss Risk Score; the association of occupation, gender, noise exposure, and age with hearing level at 4 frequency with $\mathrm{HL}>25 \mathrm{~dB}$ and across 2 to 8 frequencies with $\mathrm{HL}>20 \mathrm{~dB}$ and the results of the Logistic model of hearing loss $>25 \mathrm{~dB}$ including noise exposure level, occupation, age, and gender. These cohort and control data were extracted from available sources.

Table 1 summarizes the distribution of hearing loss by Occupation and Noise Exposure levels. There was statistical association among hearing loss and occupation and noise exposure levels $(p<0.01)$.

Table 2 summarizes the distribution of hearing loss $>25 \mathrm{~dB}$ by Occupation gender. There was statistical association among hearing loss and occupation and noise exposure levels $(p<0.01)$.

Table 3 summarizes the mean age by Occupation and $\mathrm{HL}>25 \mathrm{~dB}$. There was statistical association among hearing loss and age $(p<0.01)$.

Table 4 summarize the mean percentage of $\mathrm{HL}>20 \mathrm{~dB}$ by occupation.

\section{Model}

Logistic regression by Occupation, noise exposure levels, gender and age was the designed model.

The model that fit the reviewed data is:

Logit $[\operatorname{Pr}(\mathrm{PTA}>25 \mathrm{dBHL})]=0.077$ Mean Age $+19.166 \mathrm{RN} 1+20.273 \mathrm{RN} 2$

$+12.316 \mathrm{R} 3+34.802 \mathrm{RN} 4-2.232$ male-0.719female +20.254 mixed -16.062 Oc1

+5.752 Oc2 +40.533 Oc3 + 6.214 Oc4 + 7.145 Oc5 +0.411 Oc6 -23.039

Where: $\mathrm{RN} 1$ is noise exposure level from $85-89 \mathrm{~dB}, \mathrm{RN} 2$ is noise exposure level from 90 $94 \mathrm{~dB}, \mathrm{RN} 3$ is noise exposure level from $95-100 \mathrm{~dB}, \mathrm{RN} 4$ is noise exposure level $>100 \mathrm{~dB}$.

Mixed: where results presents both results men and women and Oc Occupation categorized: Oc1 is air, navy \& army, Oc2 is transport, Oc is mining, Oc 4 Manufacturing, Oc 5 services, and Oc 6 is agriculture. 


\section{Conclusions}

We included 43 studies. The results demonstrated that hearing loss is significant by occupation, noise exposure, gender and age. However, limitations were present to analyze this hearing loss by protection and time exposure due the lack of these data on the reviewed papers. It is suggested that further analyses focus in that association, in addition the clustering of information by age rather than occupation to observe the dynamics of this relationship.

\section{Annexes Tables}

\begin{tabular}{|c|c|c|c|c|c|c|c|c|c|c|c|}
\hline \multirow{5}{*}{ Occupation } & \multicolumn{10}{|c|}{ Noise Exposure Levels } & \multirow{5}{*}{ p_value } \\
\hline & \multirow{2}{*}{\multicolumn{2}{|c|}{$\frac{85-89 \mathrm{~dB}}{\mathrm{HL}}$}} & \multirow{2}{*}{\multicolumn{2}{|c|}{$\frac{90-94 \mathrm{~dB}}{\mathrm{HL}}$}} & \multirow{2}{*}{\multicolumn{2}{|c|}{$\frac{95-100 \mathrm{~dB}}{\mathrm{HL}}$}} & \multirow{2}{*}{\multicolumn{2}{|c|}{$\frac{>100 \mathrm{~dB}}{\mathrm{HL}}$}} & \multirow{2}{*}{\multicolumn{2}{|c|}{$\frac{<85 \mathrm{~dB}}{\mathrm{HL}}$}} & \\
\hline & & & & & & & & & & & \\
\hline & $<25 \mathrm{~dB}$ & $>25 \mathrm{~dB}$ & $<25 \mathrm{~dB}$ & $>25 \mathrm{~dB}$ & $<25 \mathrm{~dB}$ & $>25 \mathrm{~dB}$ & $<25 \mathrm{~dB}$ & $>25 \mathrm{~dB}$ & $<25 \mathrm{~dB}$ & $>25 \mathrm{~dB}$ & \\
\hline & Count & Count & Count & Count & Count & Count & Count & Count & Count & Count & \\
\hline \multirow{4}{*}{$\begin{array}{l}\text { Air, Navy \& Army } \\
\text { Transport } \\
\text { Mining } \\
\text { Manufacturing }\end{array}$} & 0 & 0 & 0 & 0 & 0 & 0 & 5865 & 1149 & 0 & 0 & \\
\hline & 0 & 0 & 0 & 0 & 76 & 0 & 0 & 125 & 0 & 0 & \\
\hline & 0 & 0 & 0 & 0 & 0 & 0 & 0 & 0 & 0 & 673 & \\
\hline & 0 & 790 & 40 & 183 & 218 & 11 & 0 & 1225 & 0 & 0 & \\
\hline $\begin{array}{l}\text { Maintenance } \\
\text { Personnel }\end{array}$ & 0 & 0 & 0 & 89 & 0 & 64 & 0 & 0 & 0 & 0 & 0.000 \\
\hline \multirow{2}{*}{$\begin{array}{l}\text { Services } \\
\text { Agriculture }\end{array}$} & 0 & 568 & 0 & 0 & 0 & 0 & 0 & 65 & 0 & 0 & \\
\hline & 0 & 0 & 1595 & 8461 & 0 & 0 & 0 & 0 & 0 & 0 & \\
\hline \multirow{2}{*}{$\begin{array}{l}\text { Construction } \\
\text { Control }\end{array}$} & 258 & 0 & 24670 & 203 & 0 & 0 & 0 & 0 & 0 & 0 & \\
\hline & 0 & 0 & 0 & 0 & 0 & 0 & 0 & 0 & 1254 & 0 & \\
\hline Total & 258 & 1358 & 26305 & 8936 & 294 & 75 & 5865 & 2564 & 1254 & 673 & \\
\hline p-value & \multicolumn{11}{|c|}{0.000} \\
\hline
\end{tabular}

Table 1 Distribution of hearing loss by occupation and noise exposure levels.

\begin{tabular}{|c|c|c|c|c|c|c|c|c|}
\hline \multirow{3}{*}{ Occupation } & \multirow{2}{*}{\multicolumn{2}{|c|}{$\frac{\text { Male }}{>25 \mathrm{dBHL}}$}} & \multirow{3}{*}{$\begin{array}{c}\text { Female } \\
>25 \mathrm{dBHL} \\
>25 \mathrm{~dB}\end{array}$} & \multirow{3}{*}{$\begin{array}{c}\text { Both/Mixed } \\
>25 \mathrm{dBHL} \\
>25 \mathrm{~dB}\end{array}$} & \multirow{2}{*}{\multicolumn{2}{|c|}{$\begin{array}{l}\text { Unknown } \\
>25 \mathrm{dBHL}\end{array}$}} & \multirow{3}{*}{ Total } & \multirow[t]{3}{*}{ P_value } \\
\hline & & & & & & & & \\
\hline & $<25 \mathrm{~dB}$ & $>25 \mathrm{~dB}$ & & & $<25 \mathrm{~dB}$ & & & \\
\hline Air, Navy \& Army & 5808 & 1149 & 0 & 0 & & 0 & 7014 & 0.000 \\
\hline Transport & 0 & 0 & 0 & 0 & & 125 & 201 & \\
\hline Mining & 0 & 0 & 0 & 0 & & 673 & 673 & \\
\hline Manufacturing & 258 & 830 & 0 & 0 & & 1379 & 2467 & \\
\hline $\begin{array}{l}\text { Maintenance } \\
\text { Personnel }\end{array}$ & 0 & 153 & 0 & 0 & & 0 & 153 & \\
\hline Services & 0 & 568 & 65 & 0 & & 0 & 662 & \\
\hline Agriculture & 0 & 0 & 0 & 5129 & 0.000 & 3332 & 10056 & \\
\hline Construction & 24670 & 0 & 0 & 0 & & 203 & 25131 & \\
\hline Fire \& Policemen & 0 & 0 & 0 & 0 & & 0 & 0 & \\
\hline Control & 1139 & 0 & 0 & 0 & & 0 & 1275 & \\
\hline Total & 31875 & 2700 & 65 & 5219 & 2151 & & 47632 & \\
\hline p-value & & & & 0.000 & & & & \\
\hline
\end{tabular}

Table 2 Number of workers by Gender \& Occupation with HL > 25 dB. 


\begin{tabular}{|c|c|c|}
\hline \multirow{3}{*}{ Occupation } & \multicolumn{2}{|c|}{ Mean Age } \\
\hline & \multicolumn{2}{|c|}{$\mathrm{HL}$} \\
\hline & $<25 \mathrm{~dB}$ & $>25 \mathrm{~dB}$ \\
\hline Air, Navy \& Army & 62.54 & 53.56 \\
\hline Transport & . & 47.73 \\
\hline Mining & . & 48.10 \\
\hline Manufacturing & 36.36 & 40.65 \\
\hline Maintenance Personnel & . & . \\
\hline Services & 26.35 & 39.00 \\
\hline Agriculture & . & 42.79 \\
\hline Construction & 27.60 & 55.36 \\
\hline Fire \& Policemen & . & . \\
\hline Control & 27.67 & . \\
\hline p-value & \multicolumn{2}{|c|}{0.000} \\
\hline
\end{tabular}

Table 3 Mean age by Occupation with $\mathrm{HL}>25 \mathrm{~dB}$.

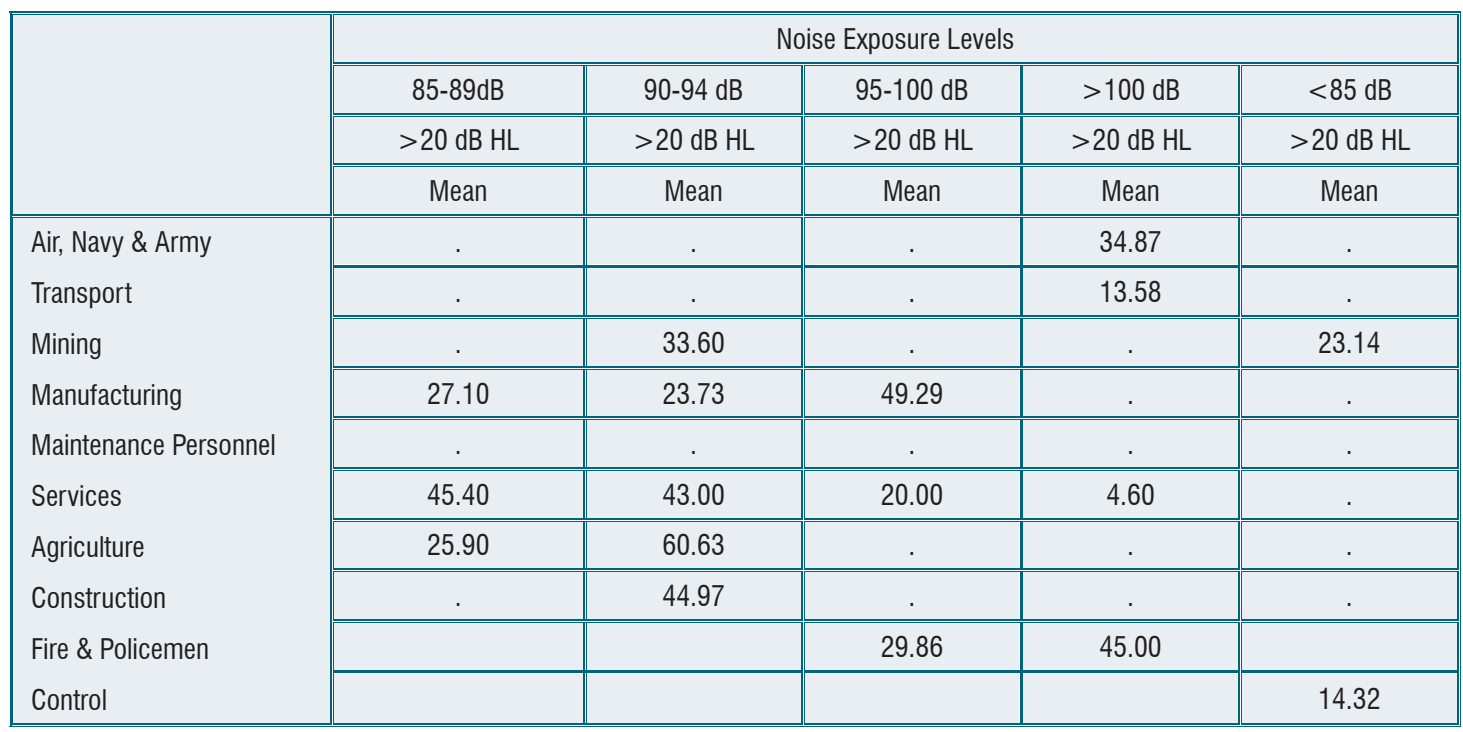

Table 4 Mean percentage of $\mathrm{HL}>20 \mathrm{~dB}$.

\section{References}

[1] Bapat, U., Tolley, N. «Temporary threshold shift due to recreational firearm use». The Journal of Laryngology and Otology. 2007, 121, 927-31.

[2] J. S., M. D. «Relation among hearing loss, age, gender, and quality of life in elderly people». International Archives of Otorrinolaryngology, 2008, 12

[3] Jang, T., Kim, B., Kwon, Y., Im, H. «The Association between Impaired Fasting Glucose and Noise-induced Hearing Loss». Journal of Occupational Health, 2011; 53:274-9.

[4] Patscheke, J., Probst, R., Schmuziger, N. «Ear Hearing: An assessment of threshold shifts in nonprofessional pop/rock musicians using conventional and extended high-frequency audiometry". Medical Problems of Performing Artists. 2008; 23:140.

[5] Alberti, P., Blair, R. «Occupational hearing loss: An ontario perspective». The Laryngoscope. 1982, 92:535-9.

[6] Godlee, F. «Health and Enviroment. Noise: Breaking the silence». BMJ British Medical Journal (Clinical research ed). 1992; 304:110-3. 
[7] Sliwińska-Kowalska, M., Zamyslowska-Szmytke, E., Szymczak ,W., Kotylo, P. «Ototoxic effects of occupational exposure to styrene and co-exposure to styrene and noise». Journal of Occupational and Environmental Medicine. 2003; 45:15-24.

[8] Talbott, E., Findlay, R., Kuller, Lh., Lenkner, L. "Noise-induced hearing Loss: A possible marker for high blood pressure in older noise-exposed populations». Journal of Occupational and Environmental Medicine. 1990; 32:690-7.

[9] Milkovic-Kraus, S. «Nosie-induced hearing loss and blood pressure». International Archives of Occupational and Environmental Health. 1990; 62:259-60

[10] Aslam, M., Aslam, M., Batool, A. "Effect of noise pollution on hearing of public transport drivers in Lahore city». Pakistan Journal of Medicine Sciences. 2008; 24:142-6.

[11] Stroup, Df Bj., Morton, Sc, et ál. Meta-analysis of observational studies in epidemiology: a proposal for reporting. 2000; 283.

[12] IBM Corp. Released 2010. IBM SPSS Statistics for Windows, Version 19.0. Armonk, NY: IBM Corp.

[13] Sliwinska-Kowalska, M., Pawelczyk, M. «Contribution of genetic factors to noise-induced hearing loss: A human studies review». Mutation Research - Reviews in Mutation Research. 2013; 752:61-5.

[14] Humes, L. E., Roberts, L. "Speech-recognition difficulties of the hearing-impaired elderly: The contributions of audibility». In: Journal of Speech and Hearing Research, 1990.

[15] Huss, M., Moore, B. C. J. Dead regions and noisiness of pure tones. In: International Journal of Audiology, 2005.

[16] Hygge, S., Ronnberg, J., Larsby, B., Arlinger, S. «Normal-hearing and hearing-impaired subjects' ability to just follow conversation in competing speech, reversed speech, and noise backgrounds". In: Journal of Speech and Hearing Research, 1992.

[17] Jerger, J., Brown, D., Smith, S. «Effect of peripheral hearing loss on the MLD». In: Archives of Otolaryngology, 1984.

[18] Jesteadt, W., Bilger, R. C., Green, D. M. Patterson, J. H. «Temporal acuity in listeners with sensorineural hearing loss". In: Journal of Speech and Hearing Research, 1976.

[19] Humes, L. E., Dirks, D. D. , Kincaid, G. E. «Recognition of nonsense syllables by hearing-impaired listeners and by noise masked normal listeners». In: Journal of the Acoustic Society of America, 1987.

[20] Humann, M. J. Hearing loss and task-based noise exposures among agricultural populations. Doctoral Ph. D. dissertation thesis. University of lowa, 1986.

[21] Hager Ld. Sound exposure profiling: a noise monitoring alternative. Am Ind Hyg Assoc J. 1998;59(6):414418.

[22] Reeb-Whitaker, Ck, Seixas, Ns, Sheppard, L, Neitzel, R. Accuracy of task recall for epidemiological exposure assessment to construction noise. Br Med J. 2004;61(2):135-

[23] Seixas, Ns, Sheppard, L, Neitzel, R. Comparison of task-based estimates with full-shift measurements of noise exposure. Am Ind Hyg Assoc J. 2003;64(6):823-829.

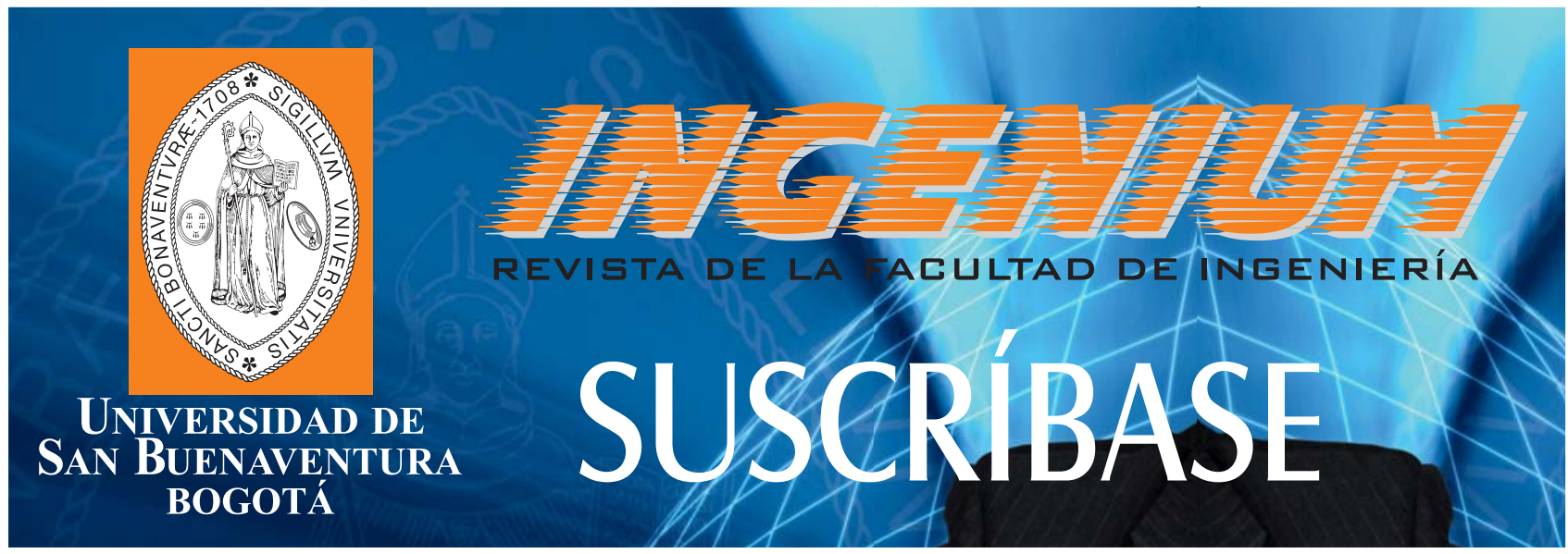

